Anuário do Instituto de Geociências - UFRJ

FORAMS 2006

\title{
Stable isotope composition of Cretaceous benthic foraminifera: Biological and environmental effects
}

\author{
Oliver Friedrich ${ }^{1}$; Gerhard Schmiedl ${ }^{2} \&$ Helmut Erlenkeuser ${ }^{3}$ \\ ${ }^{1}$ Bundesanstalt für Geowissenschaften und Rohstoffe, Stilleweg 2, 30655 Hannover, Germany \\ oliver.friedrich@bgr.de \\ ${ }^{2}$ Institut für Geophysik und Geologie, Universität Leipzig, Talstrasse 35, 04103 Leipzig, Germany \\ ${ }^{3}$ Leibniz-Labor für Altersbestimmung und Isotopenforschung, \\ Universität Kiel, Max-Eyth-Str. 11, 24118 Kiel, Germany
}

The stable carbon and oxygen isotope composition of different benthic foraminiferal species of the latest Campanian and earliest Maastrichtian from Ocean Drilling Project Hole 690C (Weddell Sea, southern South Atlantic, 1800 $\mathrm{m}$ paleowater depth) have been investigated. The total range of measured isotope values of all samples exceeds $\sim 4 \%$ for $\delta^{13} \mathrm{C}$ and $1.1 \%$ for $\delta^{18} \mathrm{O}$. Carbon isotope values of proposed deep infaunal species are generally similar or only slightly lower when compared to proposed epifaunal to shallow infaunal species. Inter-specific differences vary between samples probably reflecting temporal changes in organic carbon fluxes to the sea floor. Constantly lower $\delta^{13} \mathrm{C}$ values for Pullenia marssoni and Pullenia reussi suggest the deepest habitat for these species. The strong depletion of $\delta^{13} \mathrm{C}$ values by up to 3\%o within lenticulinids may be attributed to a deep infaunal microhabitat, strong vital effects, or different feeding strategy when compared to other species or modern lenticulinids. The mean $\delta^{18} \mathrm{O}$ values reveal a strong separation of epifaunal to shallow infaunal and deep infaunal species. Epifaunal to shallow infaunal species are characterized by low $\delta^{18} \mathrm{O}$ values, deep infaunal species by higher values. This result possibly reflects lower metabolic rates and longer life cycles of deep infaunal species or the operating of a pore water $\left[\mathrm{CO}_{3}^{2-}\right]$ effect on the benthic foraminiferal stable isotopes.

Pyramidina szajnochae shows an enrichment of oxygen isotopes with test size comprising a total of $0.6 \%$ o between 250 and $1,250 \mu \mathrm{m}$ shell size. Although $\delta^{13} \mathrm{C}$ lacks a corresponding trend these data likely represent the presence of changes in metabolic rates during ontogenesis. These results demonstrate the general applicability of multi-species stable isotope measurements of pristine Cretaceous benthic foraminifera to reconstruct past microhabitats and to evaluate biological and environmental effects on the stable isotope composition. 